\title{
POLÍTICAS DE LA PALABRA EN EL DEBATE POÉTICO ESPAÑOL CONTEMPORÁNEO
}

\author{
Laura SCARANO \\ Universidad Nacional de Mar del Plata (Argentina)
}

En el debate poético español de las dos últimas décadas, la poesía se ha convertido en un espacio de lucha, donde polemizan posturas ideológicas a menudo encontradas, que superan ampliamente las frecuentes crisis o rupturas generacionales a que nos tiene acostumbrado el campo intelectual peninsular. Se trata sin duda de un debate estético de mayor calado, que enlaza con las interpretaciones antagónicas que suscita nuestro crispado escenario cultural posmoderno. Un par de interrogantes pueden situar nuestra reflexión en las coordenadas de esta polémica:

1. ¿Pueden coexistir hoy dos lecturas antinómicas (una tildada de «reaccionaria» y la otra «progresista», de manera un tanto ligera) de una categoría filosófica como la de posmodernidad?

2. ¿Existen dos reescrituras estéticas del legado de las vanguardias históricas (más de cincuenta años después): una neovanguardia culturalista, autorreferencial y de marcado escepticismo gnoseológico (triunfante en la España de los años 70) frente a una posvanguardia realista, de reflexión ética y fe en la capacidad perlocucionaria de la palabra (recuperada a partir de los años 80 )?

Las epistemologías del fin construyeron un modelo poético de clausura autotélica del lenguaje, frente a las epistemologias de la diferencia y la acción política del discurso, que apuestan por una nueva utopía de compromiso social v alianza del arte con la historia. La clave radica en saber cuál de estas posturas 
se impondrá en el debate estético del nuevo siglo y milenio. Si es cierto que en la morada de la posmodernidad hay lugar para diferentes habitaciones (Candel Vila), la pregunta radica en saber si la aparente irreductibilidad de las antinomias arriba planteadas no convierte esta noción en una categoría inoperante como herramienta hermenéutica.

Dos relatos van tejiendo esta compleja trama (Scarano, 2000). El relato del fin ha construido un escenario cultural donde dominan conceptos como fin de la historia, muerte del sujeto, imposibilidad de interpretación, clausura del lenguaje, autorreferencia ad infinitum, poéticas basadas en la ruptura y la transgresión lingüistica, inoperancia social, reificación del margen para el arte, reclusión del artista en los suburbios de la historia frente al monopolio del mercado y los mass media y la hegemonía globalizadora del pensamiento único... El relato del reconocimiento opone otras nociones antagónicas: políticas de la diferencia (racial, genérica, social), énfasis en la microhistoria y la privacidad, apuesta por el realismo como modo discursivo frente a la hegemonía del significante y sus rupturas, nueva conceptualización de la categoría de ficción como artificio necesario y verosímil, fe en la capacidad comunicativa del lenguaje, creencia en la literatura como intervención social, recuperación de los contextos y del espacio de la sentimentalidad e intimidad, reivindicación de las «morales de la escritura» (Todorov) y «ética del oficio» (García Montero), concepción del arte como contra-poder real y resistencia civil1.

${ }^{1}$ Resulta oportuno aquí evocar las afirmaciones de uno de los teóricos más provocativos de la posmodernidad, Andreas Huyssen, quien en su agudo análisis de los derroteros culturales -cada vez más alejados de los supuestos postestructuralistas que la teoría francesa sancionara en los años 70 como dominantes- plantea esta reivindicación del hombre histórico como el verdadero «dilema del arte posmoderno». Se pregunta si aquella negación del autor y muerte del sujeto, bajo el disfraz de ser una crítica a la noción romántica e idealista de la autoría y la subjetividad, «¿no está ligada por oposición a la propia ideología que invariablemente glorifica al artista como genio?», «¿acaso la misma modernización capitalista no ha fragmentado y disuelto la subjetividad y autoría burguesa practicando ataques sobre estas nociones un tanto quijotescas?» ([1984] 1988: 231). ¿No es acaso el postestructuralismo, «allá donde simplemente niega el sujeto en general, quien lanza por la borda la posibilidad de desafiar la ideología del sujeto (como macho, blanco y de clase media) a base de desarrollar nociones alternativas y distintas de subjetividad?» (232). Para él, «rechazar la validez de la pregunta ¿quién escribe? o ¿quién habla? deja de ser una postura radical en 1984 (año en que escribe este artículo). Sencillamente reproduce a nivel de estética y teoría lo que el capitalismo como sistema de relaciones de intercambio produce a propósito en la vida cotidiana: la negación de la subjetividad en el mismo proceso de su construcción» (232). Su propuesta se orienta a enfrentar «este dilema», oponiéndose «a la letanía modernista de la muerte del sujeto, trabajando en busca de nuevas teorías y prácticas referidas a sujetos que hablan, que escriben y que actúan». Reivindicar el sujeto es reponerlo como «cuestión histórica»: «el discurso de la subjetividad ha perdido las amarras del individualismo burgués. Ciertamente no es accidental que las cuestiones de la subjetividad y autoria hayan resurgido como revancha en el texto postmoderno. Después de todo sí que importa quién habla o escriben (232). 
Ambos modelos construyen su propia genealogía estética basada en las «dos caras bifrontes de la modernidad», como bien to ha expuesto en sus artículos Joan Oleza:

]. El relato de la modernidad como reivindicación de la autonomía del arte y del genio artístico, la poética de la palabra como pura transgresión del habla y toda norma social, que enlaza con la ideología del romanticismo prometeico, de alienación y conciencia auto-dividida (Kirkpatrick), de la visión del modernismo como gesto demiúrgico y supervisión estética (Darío), del programa trascendentalista de la poesía (Jiménez) y la concepción del arte como discurso antirrepresentacional en la línea de la «teoría del aura» adorniana, que cristalizarán las vanguardias «deshumanizadas» de los años 20.

2. El relato de la modernidad desde sus fuentes ilustradas en el pensamiento revolucionario francés del siglo XVIII, el romanticismo de la «experiencia» (teorizado por Robert Langbaum), la experimentación realista-naturalista, la especulación temporal y la disidencia modernista de Antonio Machado, el frustrado programa de las vanguardias políticas de los años 30 en su intento por revincular arte y vida, las teorías del compromiso sartreano y del realismo socialista y la poesía civil y testimonial de los años 40 y 50 en España.

Pero quisiera enfocar aquí la discusión en torno a dos categorías que considero nucleares para comprender la efectiva novedad de los planteos estéticos al filo del milenio, herederos sin duda de las antinomias epistemológicas arriba planteadas, y manifiestos en las innumerables polémicas poéticas que tuvieron lugar en la península a partir de los años 80 . Dichas categorías -sujeto y sentido- habían sido proscritas por diversos enfoques estructuralistas y postestructuralistas y cierta moda neovanguardista que llegó a su clímax en Ios años 70 . Sin embargo, desde los 80 comenzaron el camino de regreso al centro de la escena no sólo poética sino teórico-literaria, epistemológica y cultural.

Estas dos nociones han sido reconceptualizadas: no son inmutables ni unidireccionales; son conceptos dinámicos que, lejos de imponer una lógica única y sin fisuras, migran en los discursos culturales de manera móvil y flexible. Aparecen hoy como las responsables de operaciones interpretativas que abren el debate en lugar de aplanarlo; redistribuyen relaciones identitarias (de género, raza, edad, lengua, territorio); abren espacios de interlocución; apuestan por articular representaciones compartidas. Sujeto y sentido son categorías-proceso, que emergen en ese ir y venir de la lectura, produciendo matrices de reconocimiento, espacios de consenso. Sujeto y sentido no son sólo formas del discurso sino figuras que conspiran conjuntamente para transformar la literatura en habla social, más allá 
de los idiolectos marginales de un lenguaje exquisito y siempre en pie de rebelión con el «lenguaje de la tribu», que un siglo de fe modernista entronizó como único rostro de la modernidad. Proponer la poesía como lenguaje del reencuentro social y no del apartamiento iluminado sería - bien mirado- reponer aquel frustrado programa de las vanguardias históricas que, al dinamitar la ratio que tiraniza la lengua, buscaban recuperar el perdido vínculo del arte con la realidad.

Pues admitamos que aquella aspiración vanguardista de fusión de arte y vida quedó congelada muchas veces en un gesto glamoroso de apartamiento a través de una lengua que reivindicó el desvío, la diferencia, la singularidad, el extrañamiento, pero perdió progresivamente el vínculo con sus lectores. Significar en contra de la norma, escribir a contrapelo del idioma común, transgredir los consensos lingüísticos mínimos terminó muchas veces obturando el proceso de intelección social. La tendencia dominante de aquella «tradición de la ruptura», como la llama Octavio Paz -enlazando simbolismo, modernismo, decadentismo hasta Ilegar al estadio climático de las vanguardias históricas-, fue sin lugar a dudas la de predicar la intransitividad del arte y negar la mímesis como fotografía falsa y reductora, pero en ese gesto se llegó a condenar la obra de arte a un «empobrecimiento de la experiencia de lo real» (como bien lo lamentó el mismo Benjamin). La hegemonía de los procedimientos, la preservación del «aura del arte» por medio del extrañamiento (Adorno) y la renuncia a la interpretación del sentido, como clave de la revolución vanguardista (Bürger), trajo aparejado muchas veces el divorcio inmediato de lo humano y la dificultad de recepción. Este modelo presentó una ambivalencia irresoluble entre intención revolucionaria y apuesta por el sinsentido y el desvío, perdiendo la relación con el receptor. Uno de los más duros cargos contra la vanguardia que innumerables críticos le han hecho es que acabó neutralizada por el mercado, como pieza de museo, reafirmando orgullosamente su origen minoritario y elitista, sin resolver la paradoja entre la utopía de un nuevo orden social y el desencuentro con el público.

Sólo parece comenzar a remontarse esta brecha abierta en el corazón de las poéticas de la modernidad, con los nuevos planteos que desde los 80 recuperan varios grupos de poetas, críticos, novelistas españoles, entroncando con la tradición subterránea del realismo contemporáneo, un «realismo posmoderno» en palabras de Joan Oleza, que resignifica las acalladas consignas también modernas del rostro más vituperado e ignorado de esa misma modernidad: la tradición del romanticismo socializante, del realismo galdosiano, de la poesía civil y comprometida de la vanguardia política y militante de los años 30 , de la poesía social y experiencial de la postguerra. Se trata de un cauce ideológico y una formalización discursiva en permanente riesgo de extinción durante el siglo $\mathrm{XX}$. que, a partir de los años 80 , la literatura española trata de articular con nuevos ojos, insuflándole nueva vida (desde las inaugurales formaciones del «sensismo» y «la otra 
sentimentalidad» a la expansión de la dominante «poesía de la experiencia» y otras vías alternativas como las del «realismo sucio», el hiperrealismo crítico, los intentos neosociales y hasta el lirismo meditativo y elegíaco que permea gran parte de las poéticas actuales). Vuelve a tener sentido hoy preguntarse por el alcance social de la escritura y su utilidad simbólica; vuelven los poetas y narradores a interrogarse por el lazo insustituible del lenguaje con la historia, por la alianza de las palabras con las cosas, por la efectiva relación del arte con el mundo material que vivimos cotidianamente.

Un sentido políticamente social supone en estas poéticas finiseculares recuperar un lugar y una función en la trama histórica: interpelar a los hombres como sujetos, producir sentidos compartidos, recuperar el lenguaje como contrato civil, como patrimonio colectivo tangible, desde su materialidad, en fin refundar la poesía y la escritura como habla social. Este sujeto y este sentido reconfigurados construyen precisamente un lugar de identidad disponible para todos. La legítima resistencia contra los conceptos uniformadores que barren las evidentes diferencias y heterogeneidad social no parece justificar el borramiento de nociones tan decisivas como las de sujeto y sentido.

Tras el telón de fondo de la universalidad, la homogeneidad y la esencial unidad racional quedaron proscritos durante buena parte de la llamada modernidad la marca social, las huellas históricas, las identidades corporales, las flexiones lingüísticas y geoculturales, en fin el autor y lector como seres más allá del papel. El vértigo del discurso y la naturaleza verbal de lo real pareció condenarnos a uno de los más fabulosos mitos que el siglo XX pareció imponernos hasta anularnos: «nada es real, todo es verbal (o virtual)». Verbal, virtual, inmaterial, atemporal, intangible, ubicuo, sin rostro ni cuerpo, sin nombre propio ni género ni edad ni color. Somos dichos; nunca decimos. No hay sujeto porque el autor es una ficción, el lector una variable de la escritura, la realidad un espejismo de los signos. Sólo hay productividad semiótica, proliferación de significantes, tras la fuerza auto-engendrante de la ideología: libertad para hacer y deshacer, pero ¿libertad de quién y para quién? ¿Qué significa esta libertad sin sujeto asumido que la ejerza? ¿No será quizás el lado oculto del juego de una ideología que para perpetuarse necesita precisamente de esta anomia y fragmentación de vínculos, de este escenario vacío? $?^{2}$

${ }^{2}$ Quizás tensar la cuerda de las -hasta hoy legitimas e irreprochables- «políticas de la diferencia» no sea más que hacerie más fácil la tarea al discurso único que aplaca el conflicto con una reivindicación ficticia, un reparto de cuotas que no hace más que perpetuar-neutralizando pero a la vez visibilizando- la discriminación que les dio origen. En esta dirección son oportunas las reflexiones que Joan Oleza hace en un reciente artículo, «Multiculturalismo y globalización: Pensando históricamente el presente desde la literatura» (Prosopopeya, 2004, en prensa): «En la medida que la ética de la diferencia supone una renuncia a todo principio de universalidad, o una exaltación acrítica de 
Quizás en este despertar del nuevo milenio haya sonado la hora de reponer la poderosa figura del hombre como responsable de su discurso, una vez extremados los caminos sin salida del simulacro ad infinitum y la virtualidad digital de esa «máquina de la visión»-según Virilio-en que se nos ha convertido el mundo. Quizás aquel programa incumplido de las vanguardias haya llegado a su «madurez histórica» (en palabras de Oleza) recién ahora y podamos plantear sin rubor una función verdaderamente social para el arte y creer en una efectiva conexión entre la literatura y la realidad.

Otra vez Andreas Huyssen acierta a distinguir con lucidez la trama compleja de estas dos flexiones antagónicas del posmodernismo, que al inicio trazamos: una que enlaza con el gesto modernista desde un eclecticismo acrítico (vinculado al postestructuralismo francés y norteamericano) que proscribe la historia, la representación, la comunicación; y otra que desarrolla un potencial crítico, reivindica el sujeto y la interpretación, y que Huyssen denomina -con notable acierto- como un «posmodernismo de resistencia». Esta postura cuestiona frontalmente la idea de modernidad cristalizada por la escuela de Frankfurt y admite que urge una revisión, ya que esa noción se ha vuelto «la manzana de la discordia». Analiza en sus textos el enfrentamiento entre la «razón ilustrada» de Habermas y la jouissance francesa o la «textualidad infinita» apropiada en USA, como plataformas antagónicas desde donde pensar la posmodernidad que, más que un «estilo», es «una condición histórica» y, por lo tanto, susceptible de nuevas e incesantes reconceptualizaciones.

Frente a la flexión dominante en los 70, para este teórico el arte se va a empezar a «desembarazar del dogma modernista de que toda cultura de masas constituye un kitsch monolítico, psicológicamente regresivo y alienante. Las expectativas de combinación experimental y la mezcla entre la cultura de masas y el modernismo parecieron prometedoras» (Huissen; en Picó, 1988: 213). Se trataría de una nueva tendencia caracterizada por un «potencial crítico» sobre el cual va a residir -profetiza- «el dilema del arte en una edad postmoderna». El desafio que plantea debe partir de un nuevo «tipo de trabajo intelectual distinto al del intelectual modernista quien tradicionalmente habló con la confianza de estar situado en la primera fila de su tiempo y de ser capaz de hablar por otros. La noción de Foucault relativa al intelectual local y específico en oposición al intelectual "universal" de la modernidad puede proporcionar una salida al dilema de quedar

\footnotetext{
la propia naturaleza, deviene fácilmente en coartada de la endogamia, del nacionalismo excluyente, del fundamentalismo religioso...») y nos alerta de sus peligros, más allá de su saludable «momento emancipatorio»: "Desde una clave multicultural [exclusivamente] no es posible fundar un sentido ampliamente compartido. No se puede explicar el mundo únicamente en clave feminista..., en clave gay, o en clave serbia, o en clave de negritud»s.
} 
encerrados en nuestra propia cultura y tradiciones a la vez que reconocemos sus limitaciones». La cultura que nazca de estas premisas ha de ser «un posmodernismo de resistencia, de resistencia incluso a ese postmodernismo fácil al estilo del "anything goes" (cualquier cosa funciona)» (Huyssen; en Picó, 1988: 241).

En el contexto estético peninsular y en muchos latinoamericanos, advertimos que lenta y trabajosamente, la literatura actual hurga en ese hueco fenomenal que nos han dejado: el hueco del sentido perdido o estallado, el de la muerte del autor, del fin de la historia y la derrota de las ideologías. El arrollador avance de tipos discursivos híbridos y mixtos como la crónica, la no ficción, el auge del ensayo, la necesidad de contar historias como pulsión antropológica, el relato de vida y su productividad para la ciencia y aún para la moda massmediática de los talko reality shows, la flexión autobiográfica devorando todos los géneros, un realismo aggiornado que aprovecha la experimentación formal y una posvanguardia que apuesta por construir consensos -superado su afán meramente iconoclasta-, son algunos de los síntomas de esta mutación ideológica y discursiva.

La poesía española de las últimas dos décadas ha sido fiel reflejo de esta lucha. La lucha por recuperar un lenguaje que nos comunique más allá de los ghettos privados de nuestras sesiones frente a ordenadores y computadoras; la lucha por consolidar vínculos que oponer a una globalización que bajo la ficción homogeneizadora del mercado único, avanza letalmente con una fragmentación disgregadora. La lucha por una literatura que nos reconcilie con nuestras identidades sucesivas (la del lugar donde vivimos, la de las lenguas que hablamos, del sexo que practicamos, de la edad que atravesamos, los gustos que reivindicamos, el arte que disfrutamos y no sólo las marcas comerciales que consumimos). Es cierto que no somos un sujeto único, cartesiano y racional pero también es cierto que vivimos cotidianamente la experiencia de ser sujetos por lo que hacemos, lo que leemos, los hijos, amigos y familia que tenemos, los lugares donde trabajamos. Todos ellos son espacios de articulación individual y comunitaria, pública y privada. Y la poesía y la literatura actual se han lanzado a reinterpretar estos lugares desde un lenguaje que pasó ya por la prueba de la fractura y la rebelión, que se renovó en el exilio y la subversión de las normas y que busca hoy reencontrar su frustrada vocación comunicativa, su ambivalente capacidad referencial, su nunca perdida apuesta por significar, por recuperar su naturaleza originaria de herramienta material de un ineludible intercambio social.

Cuando Charles Taylor, en su monumental estudio filosófico sobre el sujeto, habla de las fuentes del yo, postula su necesaria reposición en los discursos y traza un clima de época donde, como bien señalara Julio Ortega, «la muerte de la muerte del autor» es una noticia que se propaga y consolida. Volver al sujeto no significa creer otra vez en la falacia genética y positivista de su autoridad omnipotente sobre los significados de la escritura ni en la ingenua reversibilidad de texto 
y vida, sino que apuesta a construir un circuito de ida y vuelta, una inscripción del hombre como nombre, cuerpo, historia, experiencia, en el orden del discurso. Este «retorno del sujeto» (más pasional que racional) reemplaza la concepción del hombre cristalizada en los antiguos mitos de clase, pueblo, partido, nación, sin declarar a éstos inexistentes, sino abordándolos desde sus historias particulares de inserción, desde sus usos y funcionamientos. Las decisivas categorías de heteroglosia y polifonía, formuladas por Bajtín hace décadas, vienen a ocupar hoy el lugar de los antiguos mitos del monopolio del yo, junto con realineamientos de paradigmas, mezcla de estilos, irreverencia ante los cánones establecidos, explosiones retóricas, etc ${ }^{3}$.

El afán de contar historias penetra todos los géneros como gesto semiótico, pero contamina hoy especialmente la poesía última de una intencionalidad pseudo-antropológica, emulando el llamado «relato de vida» (Arfuch). No se trata de la escritura de un previo exterior a su narración; por el contrario, se modela y da forma discursiva a un torbellino de experiencias y sensaciones vividas, que sólo se comprenden desde el orden que impone la escritura. Estas fábulas poéticas no aspiran a una representatividad absoluta, sino fragmentaria; no proponen una totalidad sino que admiten la incompletud; sugieren sentidos que siempre exceden su contexto y las identidades de esos personajes se construyen en la misma trama de sus relatos. Pero dibujan con convicción siluetas reconocibles de nuestro imaginario urbano, que nos interpelan proponiéndonos inequívocas posiciones de sujeto y trazados de sentido posibles para que entremos en el juego más potente de la literatura: el «como si» de simularnos otros y nosotros, vivir otras vidas, actuarnos en los perfiles de papel de esos seres, sentimientos, reflexiones que potencia la escritura. La poesía de estas últimas décadas ha logrado encapsular en el relato de peripecias y emociones lo que la sociedad entiende por «vidas corrientes», el ser común, el individuo gris, ni célebre ni marginal, atrapado en su fotografia doméstica, capturado en sus hábitos y relaciones con los objetos, personas, lugares: es el «momento plebeyo» del que habló Gramsci, como un espacio susceptible de ser compartido, donde sujeto y sentido conspiran de modos imprevisibles pero contundentes para suscitar efectos, afectos, relaciones, que trascienden el cerco del lenguaje.

${ }^{3}$ Estas reflexiones generales son retomadas y puestas a funcionar en la lectura crítica de una de las obras más provocativas, a mi juicio, de estas últimas décadas en España, la poesia de Luis García Montero. Para un análisis del funcionamiento de estas categorías --sujeto y sentido- remito a los tres capítulos de mi libro Las palabras preguntan por su casa. La poesía de Luis Garcia Montero (2004), en cuanto a «los ritos de la intimidad», «las microhistorias de la vida cotidiana» y «la escenificación ficcional del yos. 
Apaciguados hoy muchos de los fervores estructuralistas, vemos que afortunadamente ya no es posible eliminar de la mesa de discusiones en torno al género la idea de valor y acción, efecto y creencia, sujeto y sentido, cuerpo e historia. El estudio de la literatura como acto más que como mero discurso abre una nueva agenda de problemas apasionantes que restituyen la capacidad de interpelación social del arte. La integración de la enunciación y la situación contextual, los universos de discurso implicados en el texto, las huellas de raza, edad, región, género, historia son dotados de legítimas significaciones. Los efectos in:plicados en la lectura y recepción, la comprensión de los procesos de eficacia simbólica, manipulación y conflicto constituyen categorías que abren la discusión sobre la literatura y el arte como fuerza social y potente configurador de identidades culturales, en lugar de aplanar el debate únicamente a sus superficies retóricas.

Como lectores de poesía, contemplamos hoy que se ha vuelto un obstáculo el conocido dogma de la «obra abierta» (hipostasiado hasta el delirio) y su deriva incesante en una semiosis eternamente inacabada. Recuperar el espacio para una interpretación libre de sujeciones dogmáticas, como quiso el postestructuralismo de los años 70 y 80 , no significa rendirnos a la idea del perpetuo descontrol y la fuga irresistible de los signos que impiden cualquier significación culturalmente consensuada. Expulsar al sujeto, disolver el referente, renunciar a cualquier vínculo con las cosas, bajo la excusa de que la literatura sólo es un trabajo con los signos verbales, no parece admisible ya, porque esos signos son usados por usuarios, transportan sentidos en la historia de una cultura, son motivos de lucha, confrontación o acuerdo, como bien lo anticipara Bajtín hace décadas. Excluir estas categorías del arte nos condena a aceptar una falacia hoy día insostenible: por un lado está el lenguaje y por el otro las cosas, por un camino va el arte y por otro irremediablemente paralelo discurre lo real, como dos orbes fatalmente incomunicados.

Cuando pensamos qué nos entrega la poesía actual, invariablemente coincidimos: palabras. Pero palabras que nos remiten a cosas, objetos, personas, cuerpos, historias... Lugares y tiempos; colores y edades; etnias y dialectos; sexos y nombres... Otra vez: actos, pasiones, afectos, efectos. Imágenes y sonidos, pero también sentidos y experiencias. Mientras cierta tradición crítica sacralizó el género lírico, despojándolo de su carácter artificial e histórico (de su naturaleza de «texto de cultura»), nuevas aproximaciones teóricas nos incitan a obedecer la verdad que nos dicta el más común y universal de los sentidos: la poesía es ante todo cuestión de palabras y las palabras son patrimonio de los hombres. El autor, el lector, restauran la primacía de la presencia del hombre en su lenguaje, de su necesaria subjetividad articulada (no tiranizada) por las palabras que pronuncia. Esta certidumbre difusa de sus huellas en el discurso como habla social, en la elección de las palabras como gesto ideológico, se fortalece en un horizonte cul- 
tural de pérdida de certezas y debilitamiento de los lazos comunitarios. No es el azar de los signos en perpetuo devenir el que rige estos poemas, sino un orden narrativo y una orientación ética e ideológica que proyecta una experiencia donde podemos situarnos, sin traicionar nuestra individualidad.

Aquí reside el mayor desafío de las propuestas poéticas actuales, que justifica el debate y enaltece las vitales polémicas peninsulares: ¿qué nos hace la poesía?, ¿qué hacemos con ella?, ¿qué sucede en el mundo a partir del poema?, ¿qué sucede en el poema al escribir el mundo? Trazar algunos de los rostros posibles de nuestra mudable identidad en un discurso que se ofrece como receptáculo para articularnos, supone postular una dimensión verdaderamente política de la escritura, sin ignorar sus catálogos ficcionales, pero reponiendo la figura del hombre histórico como indiscutible protagonista de la poesía ${ }^{4}$.

+ Un análisis más detenido y fino de estas cuestiones se encuentra en el capítulo 3 de mi libro Luis Garcia Montero, la escritura cono interpelación (2004), donde paso revista no sólo a las polémicas poéticas a partir de los 80 , sino a una constelación de rótulos, juegos de poder y estrategias de imposición de grupos. Asimismo, cabe agregar que una síntesis de las líneas generales de este trabajo fue leída en el VII Congreso Argentino de Hispanistas en mayo de 2004 cn la ciudad de Tucumán (Argentina). 


\section{BIBLIOGRAFÍA}

ADORNo, Theodor, Notas de literatura, Barcelona, Ariel, 1980.

- Teoría estética, Buenos Aires, Hyspamérica, 1983.

ARFUCH, Leonor, El espacio biográfico. Dilemas de la subjetividad contemporánea, Buenos Aires, FCU, 2002.

BA.TIN, Mijaíl, Estética de la creación verbal, Madrid, Siglo XXI, 1985.

- Fragmentos sobre el otro (Yo también soy), México, Taurus, 2000.

Benjamin, Walter, Tentativas sobre Brecht. Iluminaciones 3, Madrid, Taurus, 1987.

Bourdieu, Pierre, Las reglas del arte. Génesis y estructura del campo literario, Barcelona, Anagrama, 1995.

BRECHT, Bertold, El compromiso en literatura y arte, Barcelona, Península, 1984.

CAlinescu, Matei, Cinco caras de la modernidad, Madrid, Tecnos, 1991.

CANDEl VIla, María Consuelo, el realismo dialéctico en las poéticas de L. Rosales, A. González y L. García Montero, Tesis Doctoral dirigida por Joan Oleza, Universidad de Valencia, 2001.

CASTORIADIs, Cornelius, El imaginario social, Montevideo, Altamira, 1993.

EAGLeton, Ferry, Ideología. Una introducción, Barcelona, Paidós, 1997.

- Las ilusiones del posmodernismo, Buenos Aires, Paidós, 2004.

Elias, Norbert, Sociología fundamental, Barcelona, Gedisa, 1999.

Garcia Montero, Luis, Confesiones poéticas, Granada, Diputación, 1993.

- Aguas territoriales, Valencia, Pre-Textos, 1996.

HUYSSEN, Andreas, «En busca de la tradición, vanguardia y posmodernismo en los años 70», en J. Picó (ed.), Modernidad y posmodernidad, Madrid, Alianza, 1988, pp. 141-164.

- «Cartografía del postmodernismo», ibídem, pp. 189-248.

KIRKPATRICK, Susan, Las románticas. Escritoras y subjetividad en España 1835-1850, Madrid, Cátedra, 1991.

LANGBAUM, Robert, La poesía de la experiencia, ed. de Julián Jiménez Hefferman, Granada, Comares, 1996.

Muñoz, Luis (ed.), El lugar de la poesía, Granada, Diputación, 1994.

OLEZA Simó, Joan, «La disyuntiva estética de la posmodernidad y el realismo», Compás de Letras, 3 (1993), pp. 113-126.

- «Al filo del milenio: las posibilidades de un nuevo realismo», Diablotexto, 1 (1994), pp. 79-104.

- «Un realismo posmoderno», Ínsula, 589-590 (1996), pp. 39-42.

- «Una nueva alianza entre historia y novela. Historia y ficción en el pensamiento literario de fin de siglo», en José Romera Castillo, Francisco 
Gutiérrez Carbajo y Mario García-Page (eds.), La novela histórica a finales del siglo XX, Madrid, Visor, 1996, pp. 81-95.

- «Multiculturalismo y globalización. Pensando históricamente el presente desde la literatura», Prosopopeya (en prensa; material facilitado por el autor).

ORTEGA, Julio, «Identidad y posmodernidad en América Latina», Estudios, 3.6 (1995), pp. 9-22.

RODRíguez, Juan Carlos, La norma literaria, Madrid, Debate, 2001.

SCARANO, Laura, «La otra posmodernidad (Reflexiones sobre España desde Argentina)», Celehis, 9.12 (2000), pp. 257-281.

- «Las palabras preguntan por su casa». La poesia de Luis Garcia Montero, Madrid, Visor, 2004.

- Luis García Montero, la escritura como interpelación, Granada, Atrio, 2004.

TAYLOR, Charles, Fuentes del yo, Barcelona, Paidós, 1996.

Todorov, Tzvetan, Critica de la crítica, Buenos Aires, Paidós, 1991.

VIRILIO, Paul, La máquina de la visión, Madrid, Cátedra, 1989. 